\title{
Descrição de imaturos de quatro espécies de Asphondyliini neotropicais e nota taxonômica sobre Asphondylia maytenuse Maia \& Couri (Diptera, Cecidomyiidae)
}

\section{Valéria Cid Maia ${ }^{1}$}

\begin{abstract}
Description of immatures of four Neotropical species of Asphondyliini and taxonomic note on Asphondylia maytenuse Maia \& Couri (Diptera, Cecidomyiidae). Pupa of Stephomyia espiralis Maia, 1993, and larvae of Asphondylia communis Maia \& Couri, 1992 and Proasphondylia guapirae Maia, 1993 are described and illustrated. Asphondylia maytenuse Maia \& Couri, 1992 is transfered to Bruggmanniella Tavares, 1909 and its larva is characterized.

KEY WORDS. Asphondylia, Bruggmanniella, Proasphondylia, Stephomyia, Cecidomyiidae, Diptera
\end{abstract}

MAIA \& COURI (in MAIA et al. 1992) descreveram Asphondylia communis Maia \& Couri, 1992 e A. maytenuse Maia \& Couri, 1992. MAIA (1993a,b) descreveu Proasphondylia guapirae Maia, 1993 e Stephomyia espiralis Maia, 1993, respectivamente. As larvas das três primeiras espécies e a pupa da última não constaram nas descrições originais por falta de material. Excursões mensais realizadas na Restinga da Barra de Maricá (Maricá, Rio de Janeiro) durante todo o ano de 1997 permitiram a coleta destas fases que são aqui descritas.

Os Asphondyliini neotropicais possuem cerca de 130 espécies em 21 gêneros descritos, 18 dos quais endêmicos. Dos gêneros aqui estudados, apenas Asphondylia Loew, 1850 não é endêmico.

Asphondylia maytenuse Maia \& Couri, 1992, é transferida para Bruggmanniella Tavares, 1909, com base em caracteres da pupa, macho e larva.

\section{MATERIAL E MÉTODOS}

No período de janeiro de 1997 a janeiro de 1998, foram realizadas coletas mensais na Restinga da Barra de Maricá, Rio de Janeiro com o objetivo de coletar galhas induzidas por Asphondylia communis, A. maytenuse, Proasphondylia guapirae e Stephomyia espiralis.

As diferentes galhas foram transportadas, separadamente, em sacos plásticos fechados e etiquetados, para o laboratório de Diptera do Museu Nacional, Rio de Janeiro, onde foram abertas com um bisturi e examinadas com auxílio de um estereomicroscópio.

As larvas e pupas encontradas no interior das câmaras internas das galhas foram removidas e montadas em lâminas permanentes, segundo metodologia de MAIA et al. (1996).

O material estudado foi incorporado à coleção de Diptera do Museu Nacional, Rio de Janeiro.

1) Museu Nacional, Departamento de Entomologia. Quinta da Boa Vista, São Cristóvão, 20940-040 Rio de Janeiro, Rio de Janeiro, Brasil. Bolsista CAPES. 


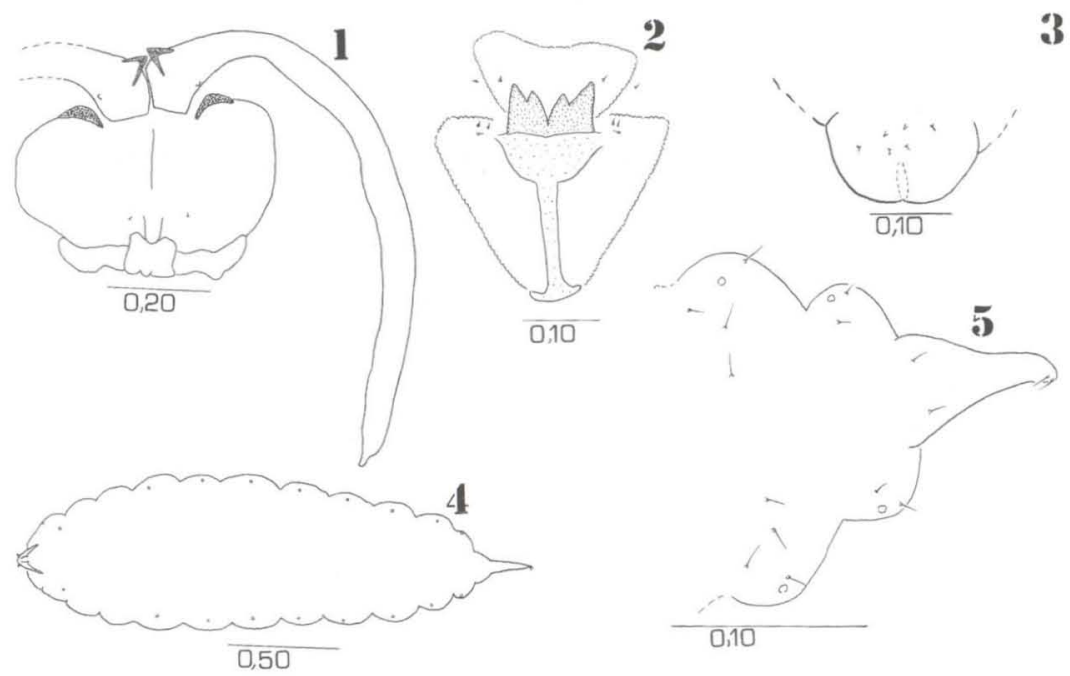

Figs 1-5. (1) Pupa de Stephomyia espiralis, região cefálica (ventral); (2-3) larva de Asphondylia communis: (2) espátula protorácica e papilas associadas (ventral); (3) segmento terminal e papilas (dorsal); (4-5) larva de Proasphondylia guapirae: (4) aspecto geral, ventral; (5) segmento terminal e papilas, dorsal. Escalas em milimetros.

\section{RESULTADOS}

\section{Descrição da pupa de Stephomyia espiralis Maia, 1993 (Fig. 1)}

Pupa pouco esclerotinizada. Comprimento: 3,0 mm ( $\mathrm{N}=2)$. Região cefálica (Fig. 1): chifres antenais curtos, porém conspícuos; cerda apical reduzida $(0,025$ $\mathrm{mm}$ de comprimento); um par de papilas faciais inferiores com cerda; papilas faciais laterais ausentes; margem superior da cabeça espessada lateralmente. Região torácica: espiráculo protorácico digitiforme e relativamente curto $(0,04 \mathrm{~mm}$ de comprimento); cobertura das asas atingindo a margem posterior do segmento abdominal III; cobertura das pernas anteriores e médias subiguais, atingindo a margem posterior do segmento abdominal $\mathrm{V}$; cobertura das pernas posteriores atingindo a margem posterior do segmento abdominal VI. Região abdominal: segmentos II-VIII cobertos dorsalmente por diminutos espinhos.

Material examinado: BRASIL, Rio de Janeiro: Restinga da Barra de Maricá, 1 exúvia, 06.XII.1997; V. Maia leg. e 1 pupa, 25.I.1998; V. Maia leg.

Descrição da larva de Asphondylia communis Maia et al., 1992 (Figs 2-3)

Coloração amarela. Comprimento: 1,8-2,3 mm $(\mathrm{N}=4)$. Papilas cervicais com cerda. Papilas esternais com cerda. Dois pares de papilas dorsais com cerda nos segmentos torácicos e abdominais I-VII; duas papilas com cerda no segmento abdominal VIII. Espátula protorácica (Fig. 2) com 0,29-0,34 mm de comprimento; quadridenteada, dentes internos mais curtos que os externos, haste desenvolvida. Papilas laterais e esternais cerdosas (Fig. 2). Três pares de papilas terminais (Fig. $3)$.

Material examinado. BRASIL, Rio de Janeiro: Restinga da Barra de Maricá, 4 larvas, 10.XI.1997; V. Maia leg. 

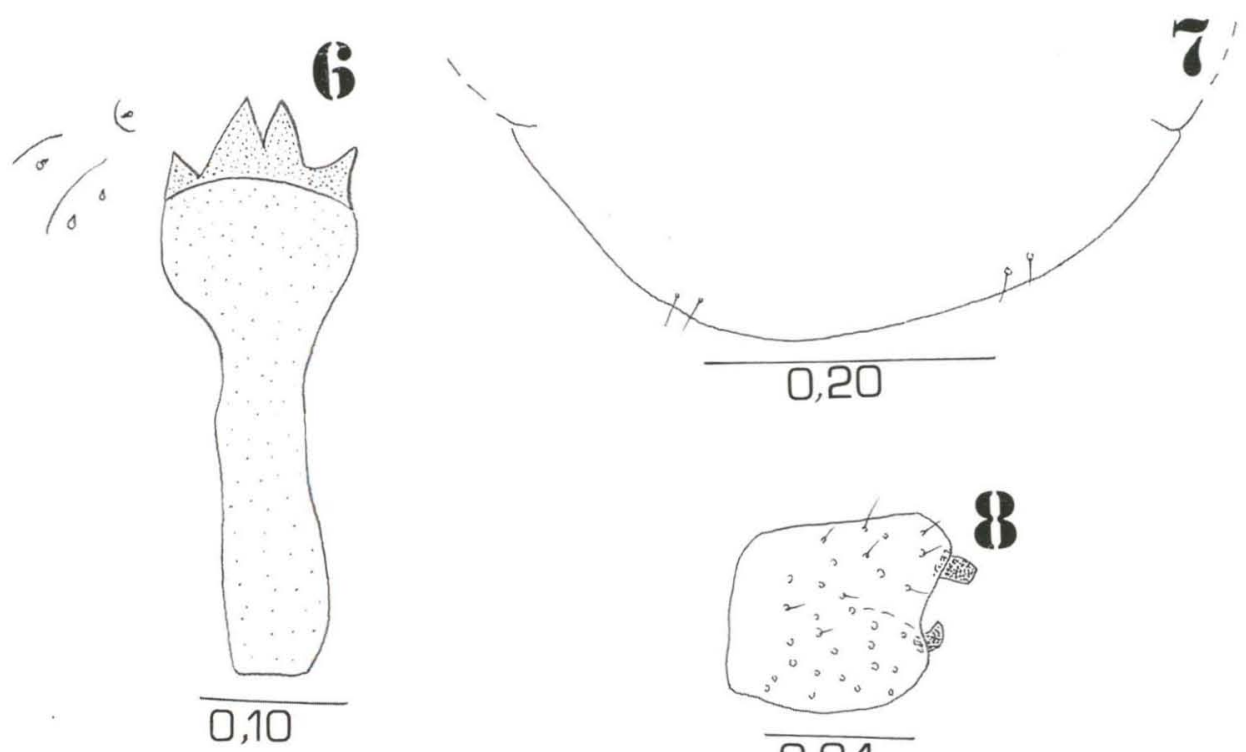

Figs 6-8. Larva de Bruggmanniella maytenuse. (6) Espátula protorácica e papilas associadas (ventral); (7) segmento terminal e papilas, dorsal; (8) macho de Bruggmanniella maytenuse, gonóstilo, dorsal. Escalas em milimetros.

\section{Descrição da larva de Proasphondylia guapirae Maia, 1993 (Figs 4-5)}

Coloração amarela. Comprimento: 2,1-2,7 mm ( $\mathrm{N}=6)$. Aspecto geral como na figura 4. Papilas do segmento cervical com cerda. Papilas esternais com cerda. Espátula protorácica ausente. Papilas laterais ausentes. Seis papilas dorsais com cerda nos segmentos torácicos e nos abdominais I-VII; duas papilas dorsais com cerda no segmento abdominal VIII. Segmento terminal alongado e afilado, em forma de "cauda" (como em Bruggmannia Tavares, 1906, Macroporpa Rübsaamen, 1916 e Pisphondylia Möhn, 1960). Papilas terminais reduzidas em número e com cerda (Fig. 5).

Material examinado: BRASIL, Rio de Janeiro: Restinga da Barra de Maricá, 6 larvas, 10.X.1997; V. Maia leg.

\section{Transferência de Asphondylia maytenuse Maia \& Couri para Bruggmanniella Tavares, 1909 e descrição da larva de Bruggmanniella maytenuse (Figs 6,7)}

Bruggmanniella maytenuse (Maia \& Couri, 1992), comb.n. Asphondylia maytenuse; Maia et al., 1992: 655-656 (Brasil, descrição da fềmea, pupa e galha).

Asphondylia e Bruggmanniella estão incluídos em Asphondyliina. Os adultos são bastante semelhantes, exceto pelo dente do gonóstilo, inteiro em Asphondylia e completamente dividido no meio em Bruggmanniella (GAGNÉ 1994). As pupas distinguem-se principalmente pelo arranjo dos espinhos faciais (presentes em Asphondylia e ausentes em Bruggmanniella) e dos espinhos dorsais do abdome (em 
Asphondylia os espinhos próximos à margem posterior dos segmentos são bem desenvolvidos e os espinhos da região mediana são consideravelmente menores; enquanto que Bruggmanniella apresenta apenas espinhos diminutos).

As larvas de Asphondylia e de Bruggmanniella assemelham-se bastante entre si. As principais diferenças relacionam-se ao arranjo das papilas laterais e à forma da espátula. Em Asphondylia, há três ou quatro papilas laterais com cerda em cada lado do segmento e a espátula é geralmente quadridenteada (em algumas poucas espécies é bidenteada); em Brugggmanniella há três papilas laterais com cerda em cada lado do segmento e a espátula pode ser quadridenteda ou tridenteada.

\section{Descrição da larva Bruggmanniella maytenuse (Maia et al., 1992) (Figs 6, 7)}

Coloração amarela. Comprimento: 2,1-2,5 $\mathrm{mm}(\mathrm{N}=5)$. Papilas do segmento cervical com cerda. Espátula protorácica com 0,3-0,4 mm de comprimento; quadridenteada, dentes externos mais curtos que os internos. Papilas esternais com cerda. Três papilas laterais com cerda (Fig. 6). Quatro papilas dorsais com cerda nos segmentos torácicos e nos segmentos abdominais I-VII; 2 papilas com cerda no segmento abdominal VIII; 4 papilas terminais com cerda (Fig. 7).

Material examinado. BRASIL, Rio de Janeiro: Restinga da Barra de Maricá, 6 larvas, 14.VIII.1997; V. Maia leg.

\section{- Notas sobre o macho de Bruggmanniella maytenuse}

$\mathrm{O}$ macho não será aqui descrito, em função de só ter sido obtido um único exemplar, porém o aspecto do gonóstilo (Fig. 8) confirma a posição da espécie em Bruggmanniella.

AGRADECIMENTOS. À Dra Márcia Souto Couri (Museu Nacional, UFRJ) pela leitura crítica.

\section{REFERÊNCIAS BIBLIOGRÁFICAS}

Gagné, R.J. 1994. The Gall Midges of Neotropical Region. Ithaca, Comstock Cornell University Press, 352p.

Maia, V.C.; M.S. Couri \& R.F. Monteiro. 1992. Sobre seis espécies de Asphondylia Loew, 1850 do Brasil (Diptera, Cecidomyiidae). Revta bras. Ent. 36 (3): 653-661.

MaIA, V.C. 1993a. Considerações sobre Proasphondylia Felt (Diptera, Cecidomyiidae) com descrições de duas espécies novas associadas com Guapira opposita (Velloso) Reitz (Nyctaginaceae). Revta bras. Zool. 10 (2): 215-218.

- 1993b. Considerações sobre Stephomyia Tavares (Diptera, Cecidomyiidae, Asphondyliidi), com descrição de quatro espécies novas associadas a Eugenia L. e Neomitranthes obscura (DC.) Legr. (Myrtaceae). Revta bras. Zool. 10 (3): 521-530.

MAIA, V.C.; M.S. MENDONÇA JR. \& H.P. ROMANOWSK. 1996. Eugeniamyia dispar gen.n. and sp.n. (Diptera, Cecidomyiidae, Lasiopteridi) associated with Eugenia uniflora L. (Myrtaceae) in Brazil. Revta bras. Zool. 13 (4): 1087-1090.

Recebido em 14.V.1998; aceito em 16.VIII.1999. 